
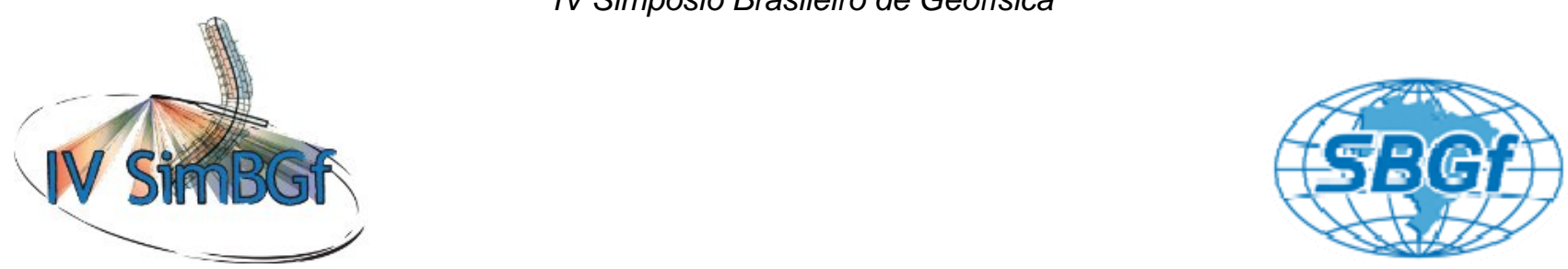

\title{
O método GPR aplicado à localização de tubulações utilizadas no abastecimento de água em Belém-Pará
}

Gerson Pompeu Pinto, pompeu@oi.com.br, Marcos Welby. C. Silva, welby@ufpa.br, Clístenes Pamplona Catete, clistenescatete@hotmail.com, Gildenilson Mendes Duarte, gildenilson@ufpa.br. CPGf-UFPA.

Copyright 2008, SBGf - Sociedade Brasileira de Geofísica

Este texto foi preparado para a apresentação no IV Simpósio Brasileiro de Geofísica, Belém, 14 a 17 de novembro de 2010. Seu conteúdo foi revisado pelo Comitê Técnico do IV SimBGf, mas não necessariamente representa a opinião da SBGf ou de seus associados. É proibida a reprodução total ou parcial deste material para propósitos comerciais sem prévia autorização da SBGf.

\section{Resumo}

Este trabalho consistiu em avaliar a viabilidade do método GPR (Ground Penetrating Radar) na localização de tubulações de aço, cimento-amianto e PVC de diversos diâmetros, utilizadas no abastecimento de água à população da região urbana do município de BelémPará. Foram realizados 6 perfis em 3 locais distintos da área urbana, com o intuito de identificar 5 alvos, utilizouse antenas de $200 \mathrm{MHz}$ e $400 \mathrm{MHz}$. Os radargramas obtidos permitiram identificar quase todos os alvos pesquisados. Apenas 1 dos 5 alvos não foi plenamente identificado, ficando de fora, apena um alvo de PVC $150 \mathrm{~mm}$. Após o estudo concluiu-se que o método GPR é muito eficaz neste tipo de aplicação e que sua utilização tem grande valia na localização das redes de abastecimento de água.

\section{Introdução}

A Geofísica pode ser aplicada a várias áreas do conhecimento, entre as quais: Geologia (prospecção de petróleo, minério e água subterrânea), Arqueologia, Geotecnia, Meio Ambiente (planejamento e monitoramento de aterros sanitários, postos de gasolina, cemitérios e etc.).

Os métodos geofísicos são ferramentas consagradas de investigação do meio físico, amplamente empregados no diagnóstico e monitoramento de áreas contaminadas e localização de objetos enterrados na subsuperfície. Em geral, a realização de levantamentos geofísicos tem por objetivo básico a identificação de possíveis zonas com propriedades físicas (condutividade elétrica, permeabilidade magnética e permissividade dielétrica) que indiquem contaminação da água subterrânea, além da definição das feições geológicas e hidrogeológicas dos locais investigados (CETESB, 2001).

Dessa forma, as informações derivadas dos levantamentos geofísicos são úteis para a locação dos poços de monitoramento, como também para o cálculo da área e do volume para remoção e remediação de solos contaminados. Além disso, ajudam a reduzir o risco de perfuração de tambores, canos, tanques e galerias subterrâneas.
Uma das principais vantagens da aplicação das técnicas geofísicas em relação aos métodos tradicionais de investigação de subsuperfície, como as sondagens, é a rapidez na avaliação de grandes áreas com custo relativamente menor. Além disso, os levantamentos geofísicos propiciam a execução de perfis contínuos, permitindo a identificação com maior precisão das variações laterais decorrentes das mudanças litológicas ou originadas pela presença da contaminação subterrânea (GREENHOUSE, 1996).

Este trabalho tratará da aplicação do GPR na localização de tubulações utilizadas no abastecimento de água à população de Belém-Pa. Esta aplicação visa contribuir nas soluções de alguns problemas decorrentes das obras de expansão e manutenção do sistema de abastecimento de água. Atualmente a Companhia de Saneamento do Pará (COSANPA) dispõe de informações desatualizadas e muitas vezes confusas sobre o posicionamento correto de suas redes, ocasionando um sério problema no desenvolvimento das obras de expansão e manutenção da rede. Dentro dessa perspectiva, a aplicação do método GPR, torna-se uma alternativa viável, com custos aceitáveis.

\section{Metodologia}

O Método do Radar de Penetração no Solo ou, abreviadamente, GPR (Ground Penetrating Radar) emprega a radiação de ondas eletromagnéticas (EM) de frequência alta (normalmente entre $10 \mathrm{MHz}$ a 2,5 GHz) a partir de uma antena transmissora colocada às proximidades da superfície do terreno. As ondas se propagam nos materiais da subsuperfície, sofrendo reflexão, refração e difração. As ondas que retornam à superfície são detectadas pela mesma antena transmissora, GPR momo-estático (Figura 1) ou por outra antena colocada próximo à antena transmissora, GPR biestático (Figura 2), fornecendo informações sobre a subsuperfície (DANIELS, 1996). 


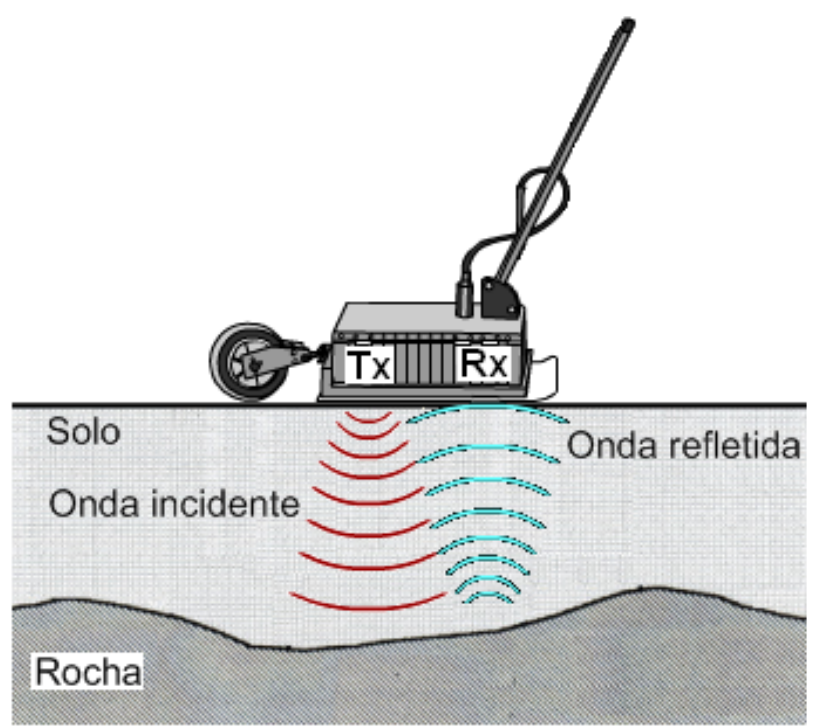

Figura 1 - Diagrama ilustrativo de um GPR monoestático.

Fonte: Pinto (2010)

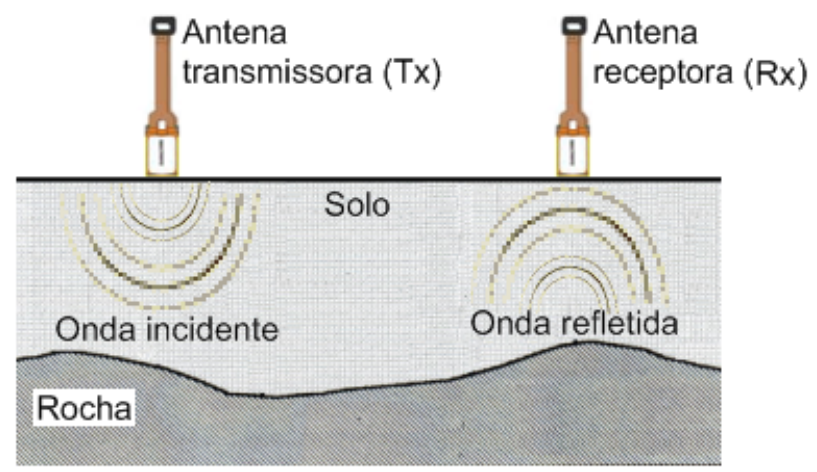

Figura 2 - Diagrama ilustrativo de um GPR biestático.

Fonte: Pinto (2010)

A propagação do sinal EM depende da frequência do sinal transmitido e das propriedades elétricas dos materiais, as quais são dependentes, principalmente, do conteúdo de água presente no solo.

O método GPR foi desenvolvido na Alemanha em 1929. Os primeiros estudos foram de identificação e mapeamento de fissuras e espessuras de geleiras na Groenlândia (DANIELS op. Cit., 1996; DAVIS e ANNAN, 1989).

No Brasil, os primeiros estudos com o GPR datam da década de 1980 (ROOSEVELT, 1991). Atualmente, organizações, universidades e outras instituições vêm trabalhando na aplicação deste método para fins diversos, tais como: meio ambiente, geologia, geotecnia, arqueologia, planejamento urbano (detecção de adutora com vazamento, instalação de aterro sanitário e outros).

\section{Resultados}

A aquisição dos dados GPR foi realizada em 6 perfis dentro da área do município de Belém, capital do Estado do Pará.

Para confrontar melhor os resultados, fez-se uso de duas antenas biestáticas blindadas de $200 \mathrm{MHz}$ e $400 \mathrm{MHz}$. Optou-se por essas antenas porque elas apresentam as características necessárias à solução dos problemas, geralmente encontrados nesse tipo de levantamento, uma vez que as tubulações estão localizadas a pouco mais de 1 metro de profundidade, em média.

\section{Perfis 1 e 2}

Esses perfis foram realizados dentro da área da COSANPA no Parque Estadual do Utinga, na rua principal que dá acesso ao lago Bolonha e Água Preta. Os perfis foram feitos sobre uma camada de asfalto, tomando o sentido Sul - Norte e perpendicular a uma adutora. O solo da região pesquisada é predominantemente argilo-arenoso. O objetivo foi localizar uma adutora de aço de 1000 mm de diâmetro, usada para o transporte de água bruta do lago do Utinga até a estação de tratamento de São Brás. A dimensão dos perfis foi de $6 \mathrm{~m}$ de comprimento com marcações feitas a cada $1 \mathrm{~m}$.

O perfil 1 foi obtido com antena de $200 \mathrm{MHz}$, onde podese observar, através do radargrama (Figura 3), a presença de um forte refletor hiperbólico, localizado entre as posições $3 \mathrm{~m}$ e $6 \mathrm{~m}$ a, aproximadamente, $1 \mathrm{~m}$ de profundidade. Esse refletor deve representar a adutora de aço procurada.

O perfil 2 foi obtido com a utilização da antena de 400 $\mathrm{MHz}$ e seu radargrama é mostrado na Figura 4, onde constata-se a presença do refletor hiperbólico, provável adutora de aço de $1000 \mathrm{~mm}$, a aproximadamente $1 \mathrm{~m}$ de profundidade e localizada entre as posições $3 \mathrm{~m} \mathrm{e} 6 \mathrm{~m}$.

Conclui-se após análise dos radargramas das Figuras 3 e 4, que em ambos os levantamentos os resultados mostrados foram bons. Entretanto, o levantamento feito com a antena de $400 \mathrm{MHz}$ foi, sensivelmente, melhor que o levantamento feito com a antena de $200 \mathrm{MHz}$, em virtude da maior amplitude do sinal.

Após as realizações dos perfis 1 e 2, foram feitas escavações em torno da adutora com a finalidade de ratificar sua localização. Fato este que pôde ser confirmado após o término das escavações.

\section{Perfis 3 e 4}

Esses perfis foram realizados no conjunto CDP na Av. Norte, bairro da Maracangalha, próximo a esquina com a Av. Júlio César. Os perfis foram feitos sobre uma camada de asfalto, tomando a sentido Sudeste - Noroeste e perpendicular aos alvos. O objetivo foi localizar duas tubulações de PVC - 150 mm e 250 mm de diâmetro, usadas no fornecimento de água co conjunto CDP. A dimensão dos perfis foi de $11 \mathrm{~m}$ de comprimento com marcações feitas a cada $1 \mathrm{~m}$. 
A Figura 5 mostra o radargrama do perfil 3, obtido com a antena de $200 \mathrm{MHz}$. Pode-se observar a presença de três refletores: P1 localizado na posição $4 \mathrm{~m}$, com aproximadamente $2 \mathrm{~m}$ de profundidade; P2 situado próximo a posição $7 \mathrm{~m}$ e quase a $1 \mathrm{~m}$ de profundidade e P3 que está logo após a posição $9 \mathrm{~m}$ e a pouco mais de $1 \mathrm{~m}$ de profundidade. Os alvos são, respectivamente, tubulação PVC - 150 mm, manilha de esgoto e tubulação PVC - $250 \mathrm{~mm}$. Nesse perfil os alvos de PVC puderam ser identificados em função do seu maior diâmetro e do maior poder de penetração da antena.

O perfil 4, obtido com a antena de $400 \mathrm{MHz}$, pode ser observado na Figura 6, onde pode-se verificar uma nova configuração dos refletores, pois não aparece o alvo P1 (tubulação PVC - $150 \mathrm{~mm}$ ), já que a configuração do range da antena não permitiu que a mesma alcançasse a profundidade do alvo. Como foi observado no radargrama da Figura 5, o refletor $\mathrm{P} 1$ encontra-se a uma profundidade de aproximadamente $2 \mathrm{~m}$, entretanto, como podemos observar na Figura 6, a profundidade máxima alcançada com o uso da antena de $400 \mathrm{MHz}$ foi de 1,80 m, o que impossibilitou a sua localização. Então têm-se: P2 (manilha de esgoto) situado próximo a posição $7 \mathrm{~m}$, quase a $1 \mathrm{~m}$ de profundidade e P3 (tubulação PVC - 250 $\mathrm{mm}$ ) que está na posição $9 \mathrm{~m}$ e a pouco mais de $1 \mathrm{~m}$ de profundidade.

Pode-se concluir após análise dos radargramas das Figuras 5 e 6, que o melhor resultado foi obtido com a utilização da antena de $200 \mathrm{MHz}$, pois com a antena de $400 \mathrm{MHz}$ o alvo P1 foi suprimido do radargrama, em decorrência do baixo poder de penetração da antena de $400 \mathrm{MHz}$, para o respectivo solo.

\section{Perfis 5 e 6}

Esses perfis foram realizados na Av. Victor da Silva, bairro da Castanheira, entre o residencial Costa e Silva e o posto dos Correios. As sondagens foram feitas sobre uma camada de asfalto, tomando a sentido Sudoeste Nordeste e perpendicular ao alvo. O objetivo foi localizar uma tubulação de cimento - amianto (C.A.) de $150 \mathrm{~mm}$ de diâmetro, usada no fornecimento de água. A dimensão dos perfis foi de $7 \mathrm{~m}$ de comprimento com marcações feitas a cada $1 \mathrm{~m}$.

O radargrama do perfil 5, obtido com a antena de 200 $\mathrm{MHz}$ é mostrado na Figura 7. Pode-se observar a presença de um refletor, associado à tubulação de C.A. $150 \mathrm{~mm}$, localizado entre as posições $6 \mathrm{~m}$ e $7 \mathrm{~m}$, a pouco mais de $0,5 \mathrm{~m}$ de profundidade.

A Figura 8 mostra o radargrama do perfil 6 , obtido com a antena de $400 \mathrm{MHz}$, onde o forte refletor hiperbólico deve ser a tubulação de C.A. - $150 \mathrm{~mm}$, entre as posições $6 \mathrm{~m}$ e $7 \mathrm{~m}$, a pouco mais de $0,5 \mathrm{~m}$ de profundidade.

Pode-se concluir através da análise dos resultados fornecidos pelos radargramas das Figuras 7 e 8 , que as informações obtidas com as antenas são equivalentes, com uma sensível melhora nos resultados fornecidos pela antena de $400 \mathrm{MHz}$, já que o alvo procurado não é um bom refletor.

\section{Discussão e Conclusões}

Dentro das perspectivas iniciais, propostas por este trabalho, o método GPR mostrou-se uma ferramenta eficaz na localização das tubulações utilizadas pela Companhia de Saneamento do Pará - COSANPA, no abastecimento de água à população da área urbana do município de Belém-PA, pois dos 5 alvos pesquisados, apenas 1 não foi plenamente identificado, em decorrência do material constituinte do alvo e da sua profundidade.

O alvo que não foi plenamente identificado pela antena de $400 \mathrm{MHz}$ foi a tubulação constituída de PVC, especificamente a de $75 \mathrm{~mm}$ de diâmetro, haja vista o baixo poder reflexivo do PVC e a pequena dimensão do alvo.

Os perfis realizados com o intuito de localizar as tubulações de cimento-amianto, foram 100\% cobertas de êxito, já que as tubulações feitas com esse material são armadas em estruturas feitas de metal, o que contribui para o seu poder reflexivo, pois o poder reflexivo do cimento-amianto é pequeno.

No que diz respeito à utilização das antenas, pode-se concluir que a antena de $200 \mathrm{MHz}$ destacou-se nos resultados obtidos, em comparação com a antena de 400 $\mathrm{MHz}$, pois a mesma foi capaz de localizar todos os alvos metálicos, de cimento-amianto e os de PVC de maior dimensão. O mesmo não ocorreu com a de $400 \mathrm{MHz}$, pois não foi capaz de localizar uma das tubulações de PVC, devido ela encontrar-se em profundidade maior que o poder de penetração da antena.

\section{Agradecimentos}

O primeiro autor agradece ao Curso de Pós-graduação em Geofísica da UFPA e à José Joaquim Melo Rodrigues - Engenheiro chefe de manutenção da Companhia de Saneamento do Pará (COSANPA). O segundo autor agradece ao suporte financeiro do Conselho Nacional de Desenvolvimento Científico e Tecnológico através do Projeto CNPq 484669/2007-9.

\section{Referências}

COMPANHIA DE TECNOLOGIA DE SANEAMENTO AMBIENTAL - CETESB. Manual de Gerenciamento de Áreas Contaminadas. Projeto de Cooperação Técnica Brasil-Alemanha/CETESB GTZ. 2. ed., São Paulo, 2001. $398 \mathrm{p}$.

DANIELS, D. J. Surface penetrating radar. The Institution of Electrical Engineers, London, United Kingdom, 1996. $300 \mathrm{p}$.

DAVIS, J. L.; ANNAN, A. P. Ground-penetrating radar for high-resolution mapping of soil and rock stratigraphy. Geophysical Prospecting, v. 37, 1989. p.531-551.

GREENHOUSE, J. P. Aplicações de Metodologias Geofísicas em Estudos Ambientais e Geotécnicos. CEA/UNESP Rio Claro, 1996, 111p. 
PINTO, G.P. O Método GPR aplicado a localização de tubulações utilizadas no abastecimento de água na região urbana do município de Belém-Pará. 2010. 96 f. Dissertação (Mestrado em Geofísica) - Centro de Geociências, Universidade Federal do Pará, Belém, 2010.

ROOSEVELT, A. C.; Moundbuilders of the Amazon: Geophysical Archaeology on Marajo Island, Brazil. San Diego: Academic Press, 1991. 495 p.

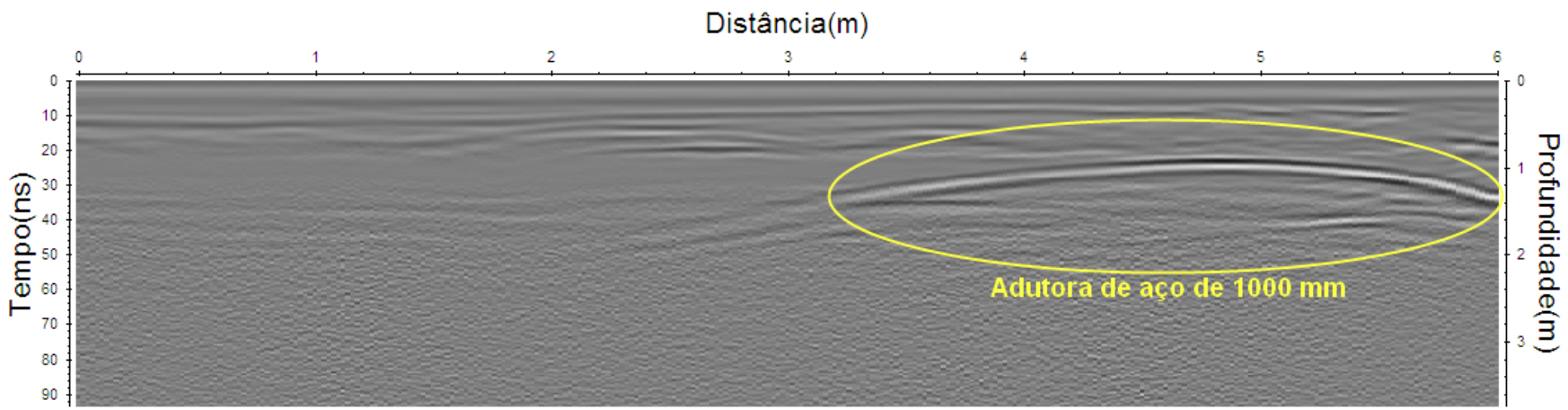

Figura 3 - Radargrama do perfil 1, usando antena de $200 \mathrm{MHz}$. O forte refletor hiperbólico deve representar a adutora de aço de $1000 \mathrm{~mm}$.

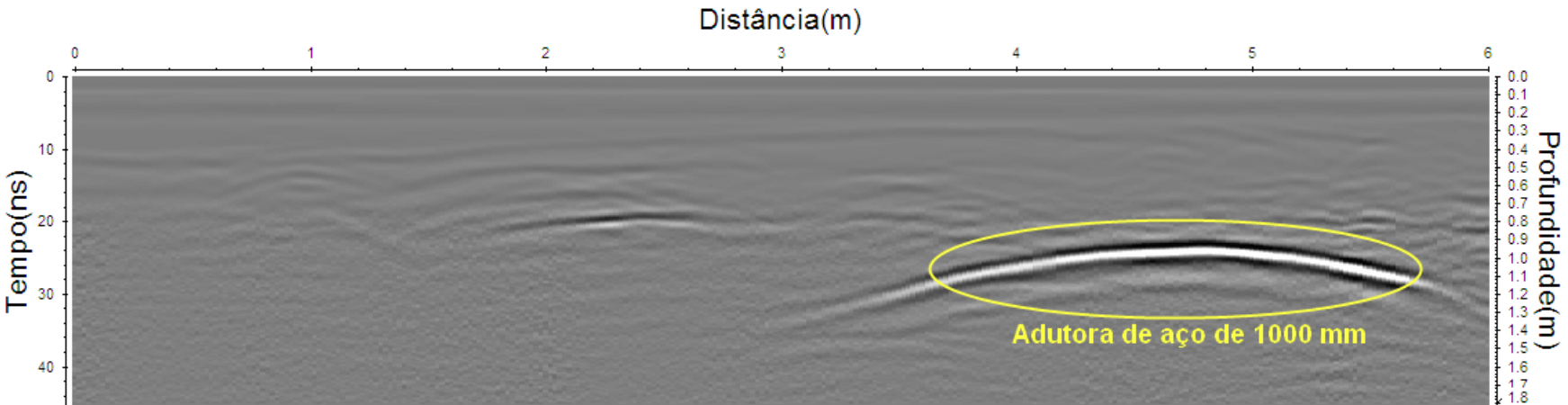

Figura 4 - Radargrama do perfil 2, usando antena de $400 \mathrm{MHz}$. O forte refletor hiperbólico deve representar a adutora de aço de $1000 \mathrm{~mm}$.

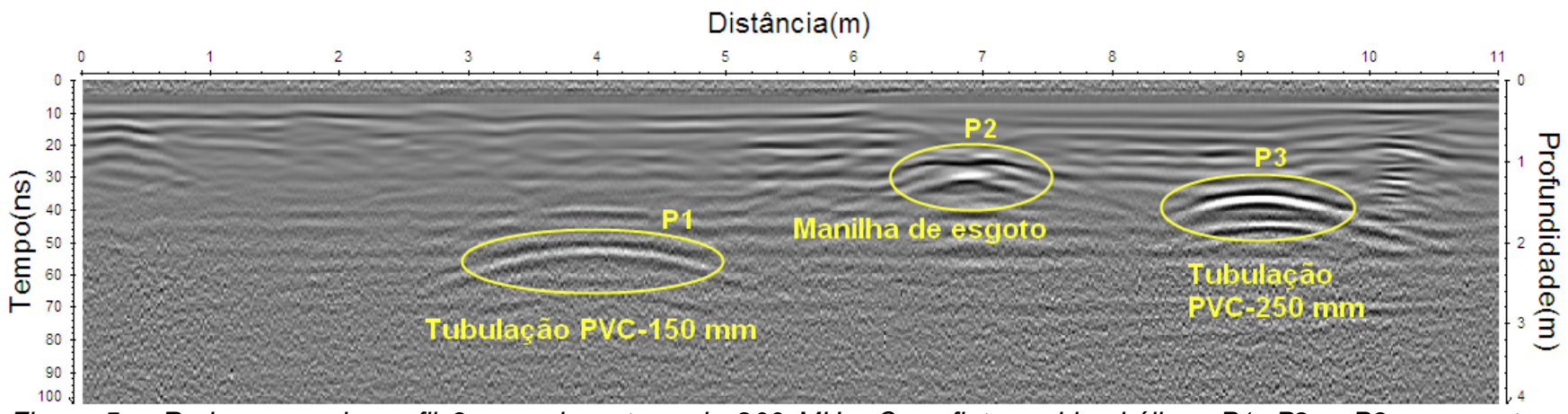

Figura 5 - Radargrama do perfil 3, usando antena de $200 \mathrm{MHz}$. Os refletores hiperbólicos P1, P2 e P3 representam, respectivamente, a tubulação PVC - $150 \mathrm{~mm}$, manilha de esgoto e PVC - $250 \mathrm{~mm}$. 


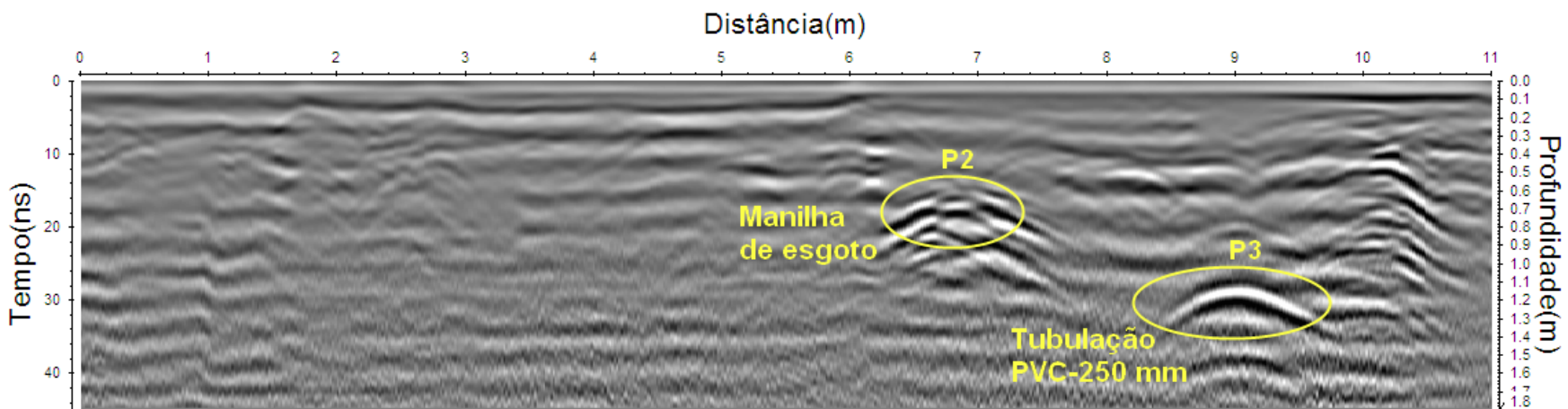

Figura 6 - Radargrama do perfil 4, usando antena de $400 \mathrm{MHz}$. Os refletores hiperbólicos P2 e P3 representam, respectivamente, a manilha de esgoto e PVC - $250 \mathrm{~mm}$.

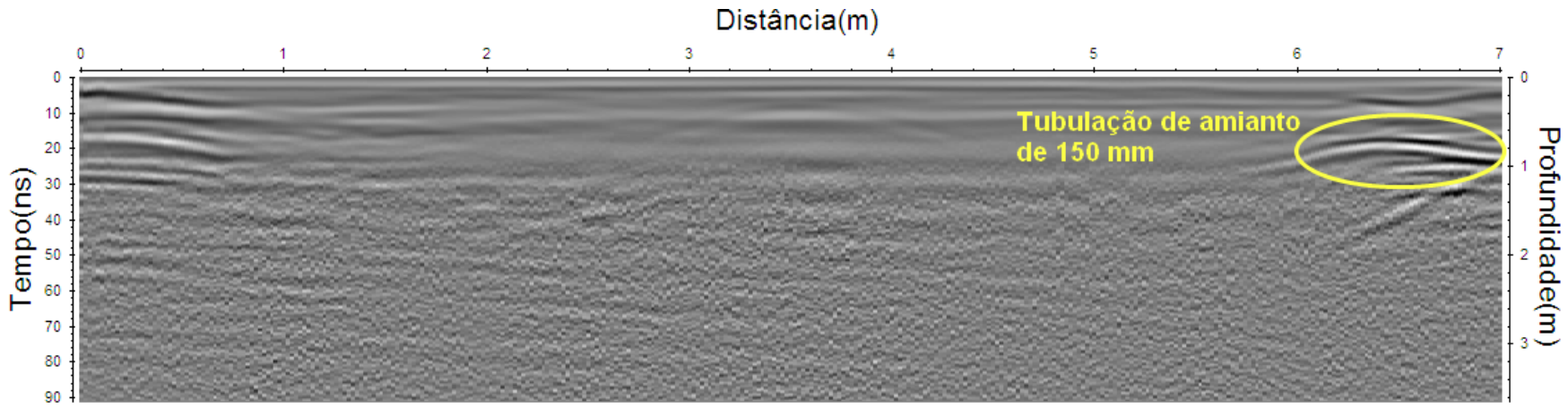

Figura 7 - Radargrama do perfil 5, usando antena de $200 \mathrm{MHz}$. O refletor hiperbólico representa uma tubulação de cimentoamianto com $150 \mathrm{~mm}$ de diâmetro.

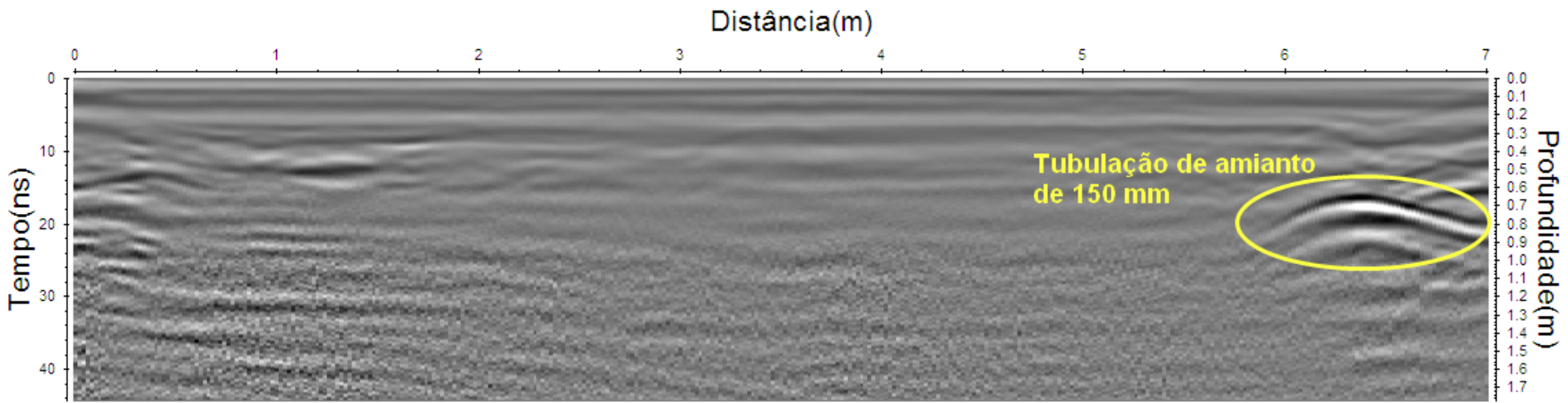

Figura 8 - Radargrama do perfil 6, usando antena de 400 MHz. O refletor hiperbólico representa uma tubulação de cimento amianto com $150 \mathrm{~mm}$ de diâmetro. 